\title{
Detrás de las palabras: usos políticos del concepto de "imparcialidad" y su función en la construcción de la historia de América en la llustración española
}

\section{Behind the words: Political uses of the concept "impartiality" and its function in the construction of the history of America in the Spanish Enlightenment}

\section{Nuria Soriano Muñoz}

\section{RESUMO}

En tiempos de renovado debate sobre el presentismo y la objetividad de los historiadores, pretendo indagar en los usos ideológicos y las funciones políticas que desempeñó el concepto de "imparcialidad" en la Ilustración española, su relación con la escritura de la historia y, más particularmente, con la conquista de América. A partir de diversos textos impresos de finales del s. XVIII e inicios del s. XIX -apologías, elogios, diccionarios $y$ otros textos literarios- y adoptando una metodología que aúna la historia cultural y de los conceptos, me detendré en cómo las élites culturales dieciochescas atribuyeron al concepto un significado positivo y necesario para construir los discursos sobre lo acontecido en 1492. Desmontar su dimensión ideológica permite pensar en la "imparcialidad" como herramienta constructora de la "diferencia", una noción que legitima y confiere prestigio a la nación española y, al mismo tiempo, vertebra una compleja red de identidades.

\section{ABSTRACT}

In a time of renewed debate about presentism and the objectivity of historians, the goal of this article is to question the ideological uses and the political functions that the concept of "impartiality" has played in the Spanish Enlightenment, its relation with the writing of history and, more specifically, with the conquest of America. Through a variety of printed texts from the late eighteenth to the early nineteenth-century -apologies, praises, dictionaries and other literary texts- and through a methodology that unites the cultural history and concepts, the focus will be on how the eighteenth-century cultural elites attributed a positive and necessary meaning to the concept to build discourses on what happened in 1492. Dismantling its ideological dimension allows understanding "impartiality" as a constructive tool to "difference", a notion that legitimates and grants prestige to the Spanish nation as well as structures a complex network of identities.

\section{PALAVRAS-CHAVE}

Imparcialidad; América Hispánica; Ilustración.

\section{KEYWORDS}

Impartiality; Hispanic America; Enlightenment. 
Las de objetividad e imparcialidad son nociones fundamentales del discurso histórico que continúan preocupando a los historiadores en la actualidad, por distintas que sean sus perspectivas, metodologías o formas de producir historia. ${ }^{1}$ Por cierto, los historiadores del presente no han sido los únicos en distinguir ambos conceptos y familiarizarse con su significado, imprescindible para comprender nuestro pensamiento y oficio (FONTANA 1999; NOVICK 1997). ${ }^{2}$ Desde tiempos muy remotos, la proyección de la mirada del historiador -el tiempo en el que se envuelve y desarrolla su producción, los motivos que promueven su escritura, la expresión de sus simpatías y antipatías, el tratamiento de los documentos- sobre su propio relato han suscitado críticas y amplias controversias entre escritores de muy diferente condición y relacionados con las estructuras de poder de forma también diversa. Las denuncias sobre el sesgo han revelado las contradicciones, el carácter problemático y difuso de un término - "imparcialidad" - cuyo significado ha ido construyéndose a lo largo del tiempo.

Durante la segunda mitad del siglo XVIII, "imparcialidad" y "parcialidad" fueron términos muy visibles en los textos producidos por las élites políticas y culturales de la metrópoli española, sobre todo en lo que se refiere a la construcción de la historia y, más particularmente, a la historia de América. Pese a lo que pudiera parecer, esas nociones poco tenían de obvias, naturales y atemporales. Al calor de los acontecimientos históricos y de las tendencias intelectuales, con una notable carga política e incluso emocional, los conceptos y las ideas conjuraban, de algún modo, las incertidumbres de los hombres del pasado estableciendo órdenes y jerarquías determinadas. Como sostenía Jean Touchard, desde la atalaya de la historia intelectual, las "ideas son válidas por lo que se hace con ellas" (DOSSE 2007, p. 50).

Que los ilustrados tuvieron un lenguaje "característico" e incluso propio con el que construyeron los discursos sobre el mundo que los rodeaba no es, a estas alturas, ninguna novedad. Siguiendo a Maravall, así lo había apuntado el lexicógrafo Pedro Álvarez de Miranda, en su intención de subrayar las connotaciones valorativas que se escondían detrás de nociones como las de patria, progreso, crítica y civilización - por citar unos pocos ejemplos- y su importancia social en el vocabulario temprano del Siglo de las Luces (ÁLVAREZ DE MIRANDA 1992, p. 44).

El estudio de tales conceptos característicos, además de arro-
1 - Algunos historiadores podrían considerar esta controversia ya agotada o superada. Sin embargo, los planteamientos de los filósofos posmodernos, el éxito de los memory studies, el empeño de los historiadores en distinguir la "memoria" de la "ciencia histórica", el auge del presentismo y la celebración de actividades académicas variadas prolongan un debate que parece no tener fin. Conmemoraciones $y$ congresos vuelven a colocar el acento en el desacuerdo existente sobre el papel del historiador en la sociedad actual, asi como en la cuestión de su implicación en su escritura y en la sociedad de su tiempo.

2 - Conviene subrayar, en cualquier caso, que imparcialidad y objetividad no son exactamente 10 mismo. Josep Fontana reflexionó sobre las diferencias entre ambos conceptos en Historia. Pasado y proyecto social. A su parecer, es inevitable que el historiador tome partido y se posicione. Sin embargo, esa postura debe ser perfectamente compatible con la pretensión de objetividad, una metodología concreta y el respeto a las fuentes primarias.

En cuanto a la noción de objetividad, su definición ha generado un amplio desacuerdo entre los historiadores, ya sea como 
jar nuevas perspectivas para comprender los problemas históricos, permite al historiador trazar lazos de cohesión social entre los grupos que los utilizaban con un mismo significado e, incluso, de cierta "lealtad" hacia ideas políticas concretas. Sin embargo, y pese al amplio abanico de términos recogidos en su obra, Álvarez de Miranda no incluye el término "imparcialidad" como noción fundamental del vocabulario de la época. ${ }^{3}$ En estas páginas me centraré, por tanto, en el estudio de la forma adjetiva en una época posterior a la analizada por el autor. Realizaré un pequeño recorrido histórico por dicho concepto a partir de las reflexiones de los historiadores y literatos, dilucidando su función y uso. Con posterioridad, prestaré especial atención a la presencia del concepto en la construcción de la historia de América (BODEKER 2013, p. 10). Con ello, no pretendo juzgar si tenían razón aquellos intelectuales que afirmaban que no existía un cronista más imparcial que Juan de Mariana (FORNER 1786, p. 74). Más bien, la cuestión reside en analizar cómo y de qué manera se deciden los criterios de imparcialidad, los presupuestos ideológicos desde los cuales se construye una idea fundamental en la escritura de la historia. ¿Cómo discernir lo que es justo de lo que no lo es? ¿Quiénes lo deciden? ¿Cómo lo hacen y en qué se apoyan?

La idea de imparcialidad debe comprenderse en el marco de unas coordenadas precisas, relacionadas a los debates políticos y filosóficos de la Ilustración, en una época preocupada por el progreso, la crítica, la civilización y la sociabilidad, así como a los debates sobre la construcción de la historia y los contrastes entre los diferentes caracteres nacionales. En ese proceso, algunas voces fueron plenamente conscientes de que las impresiones y los juicios de los observadores estaban condicionados por prejuicios y valores extraños, necesariamente subjetivos (BOLUFER 2003, p. 271). Más concretamente, la noción de imparcialidad cobró importancia en un marco cultural en el que, por un lado, la imagen de España estaba siendo cuestionada y, por otro, la apología se convirtió en la forma de expresión más acabada de la historia y la realidad colonial del momento, asumiendo formas muy variadas en sus materialidades, formatos y actores históricos (MESTRE 2003, p. 48-70; CAÑIZARES ESGUERRA 2007, p. 223-357; CASTILLA URBANO 2014, p. 9-20; DIZ 2006, p. 171-190). Muchos intelectuales de la península sostenían que los antiguos historiadores españoles eran despreciados por la crítica europea. Esa imagen negativa de España integraba, de algún modo, la identidad propia "de la generación que se hace adulta en el reinado de Carlos III" (LÓPEZ CORDÓN 2006, p. 167). Durante aspiración, pretensión, certeza o ambición inalcanzable. Peter Novick resaltó su papel como mito creador y fundador de la profesión histórica en el seno de la historiografía norteamericana.

3 - Tampoco consta en el diccionario de conceptos coordinado por Javier Fernández Sebastian y Juan Francisco Fuentes (2002). 
aquellos tiempos, eran habituales los testimonios de los historiadores que se lamentaban de la inexistencia de "escritores imparciales" proclives a defender "la memoria de nuestros héroes". Así lo señaló el jesuita desterrado en Italia Juan Nuix (1782, p. 312).

La comprensión de este marco quedaría incompleta si no se tuviera en cuenta que la polémica sobre las "Indias" cobró protagonismo en salones, folletos y tertulias, incidiendo muy estrechamente en la reputación y la imagen de España en el extranjero (GERBI 1982; PAGDEN 1993). En ese sentido, la memoria de la conquista se convirtió en un tema fundamental del debate ilustrado. A estas alturas, los argumentos de Voltaire, Ferguson, Rousseau, Montesquieu y Cadalso, entre muchos otros, son bien conocidos por los historiadores.

La impresión de geografías, traducciones, compendios y enciclopedias avivaron el debate sobre los caracteres nacionales y la construcción de mitos negativos sobre España -la imagen de un país en los márgenes de la modernidad, cruel, despótico y periférico- que dieron lugar a la composición de un número amplio de apologías de la nación española, toda una respuesta institucional a la historiografía europea por parte del gobierno de Carlos III (BAS MARTÍN 2000; CHECA BELTRÁN 2012; VÉLEZ JIMÉNEZ 2007, p. 19-41). En dichas obras, son incontables las expresiones de los autores que aseguraron mantener posiciones imparciales en consonancia con una postura que promovía los intereses de sus propios territorios (SANTANA PÉREZ 2017, p. 43-63) y, más en concreto, frente a los "ataques" que propinaban escritores franceses e ingleses contra España y sus conquistadores debido a su actitud violenta y codiciosa en el "Nuevo Mundo". Muchos escritores hicieron gala de una marcada nostalgia hacia las virtudes y los héroes del pasado peninsular. Esas expresiones se acompañaron en ocasiones de evocaciones del pasado glorioso de la conquista, de aquella realidad lejana, exótica y desconocida que continuaba siendo América.

\section{İmparcialidad y parcialidad}

Ni los adeptos a la filosofía de las "Luces" ni tampoco sus detractores inventaron el término "imparcialidad" e "imparcial." Mucho antes, el poeta madrileño Alonso de Ercilla los había usado en su Araucana, publicada a finales del siglo XVI. También en numerosos vocabularios bilingües del barroco constaba la entrada correspon- 
diente al menos desde 1608 e incluso antes. Algo similar ocurrió en Inglaterra, donde la voz "impartial" puede documentarse a lo largo y ancho del s. XVII. Si se compara con el caso inglés, las diferencias semánticas son mínimas, pues ese término significa "equitativo, desinteresado, libre de valoraciones y estima, igualitario en la distribución de justicia" (SHERIDAN 1785). Más allá del barroco, en el siglo XVIII, "imparcial" se convirtió en una voz muy popular que adquirió fuerza y un uso frecuente. Las cabeceras de algunos periódicos de la prensa periódica bien lo demuestran, pero también las traducciones, los elogios, las reflexiones, la correspondencia y los prólogos contribuyeron a esa amplia circulación de la forma adjetiva. Especialmente a partir de 1777 y hasta 1788 y, posteriormente, desde 1789 hasta 1800 , podemos encontrar un acusado incremento del uso de la palabra en comparación con las décadas precedentes.

En una gran variedad de epítomes ilustrados y liberales, podemos ver las siguientes locuciones: "odio imparcial" (ZEVALLOS 1776), "imparcial cariño" (MARIANO NIFO 1781), "todo filósofo se jacta de imparcialidad" (JUAN NUIX 1782), "ponderar con imparcialidad un hecho" (LORENZO HERVÁS 1783), "examinar con imparcialidad" (SUÁREZ DE TOLEDO 1783), "lector imparcial" (CABANILLES 1784; JOVELLANOS, 1812); "justicia imparcial" (CAPMANY 1787); "historiador verdaderamente imparcial" (CORREO DE MADRID 1788); "forastero imparcial" (ARANA DE VARFLORA 1789); "extranjero imparcial y desapasionado" (SEMPERE Y GUARINÓS 1789); "homenaje imparcial" (CANGA ARGÜELLES 1833); "crítica sana e imparcial" (MARTÍNEZ DE LA ROSA 1838).

El significado del término "imparcial" no deja lugar a dudas. La condición de imparcialidad viene a constituir una actitud, una predisposición del sujeto a no tomar partido entre opiniones o juicios sobre las cosas, es decir, sería un sinónimo de "juicio recto y actitud desapasionada o desinteresada". Derivado del latín "impartialis", el adjetivo se incluye en el Diccionario de Autoridades como "el que se mantiene sin adherir ni aplicarse a alguna parcialidad" (DICCIONARIO 1734, p. 219). Puede subrayarse, sin embargo, una segunda acepción referida, textualmente, a un individuo "retirado de la sociabilidad, de la comunicación de otros". El Diccionario de la Real Academia de 1791 definirá "imparcial" del mismo modo que el Diccionario de Autoridades, exponiendo ambas acepciones (REAL ACADEMIA 1791, p. 492). "Imparcialidad" hará, por tanto, referencia al hecho de un individuo no manifestarse en contra o a favor de alguien 
o de algo, alejándose de las exageraciones, de las sospechas y la envidia. En ese sentido, la idea se aproxima al concepto de crítica y al carácter de verdad. La segunda acepción - menos documentadarelaciona el concepto con el aislamiento y la soledad. Precisamente el concepto de sociabilidad -y de lo sociable- es una de las máximas divisas del pensamiento ilustrado, una cualidad positiva de las personas que, en opinión de los hombres y mujeres del Siglo de Las Luces, debía cultivarse (ÁLVAREZ DE MIRANDA 1992, p. 349-381; BOLUFER 2006, p. 121-148).

La relación que puede constatarse en el Diccionario de la Real Academia entre "no tomar partido" y mostrarse "exento de pasiones" con aislamiento y soledad se mantiene en las primeras ediciones de 1780 y 1791 . Ambas acepciones de "imparcial" se recogen asimismo en el diccionario de Terreros (1793, p. 73). Sin embargo, en la cuarta edición del Diccionario de la Academia (1803) se produce un cambio significativo. La acepción negativa del concepto, opuesta al concepto de sociabilidad y mantenida alrededor de veinte años, desaparecerá del volumen (1803, p. 475). Resulta interesante hacer hincapié en ese pequeño matiz que, antes de la guerra de 1808, confiere un valor netamente positivo al concepto.

Veamos una serie de ejemplos sobre el significado de la "imparcialidad" en los escritores ilustrados. Un clarividente uso de la noción puede hallarse en el elogio que el inquisidor de Valencia y filojansenista Nicolás Rodríguez Laso pronunció sobre el duque de Almodóvar, director de la Real Academia de la Historia y traductor de la Historie de Raynal, obra polémica por sus críticas a España debido a su actuación en América y uno de los compendios históricos más conocidos del momento. El salmantino Rodríguez Laso exaltaba su condición de español y calificaba al duque de imparcial (RODRÍGUEZ LASO 1795, p. 33).

Según Rodríguez Laso, el trabajo intelectual de Almodóvar demostraba su imparcialidad, su veracidad y el hecho de no haberse dejado conducir por "el espíritu de partido", una especie de compromiso con el que había defendido a la nación española de las críticas del filósofo y jesuita francés. Precisamente, la traducción de textos franceses e ingleses será una oportunidad excelente para construir diferentes grados de imparcialidad en función de su autoría y, como veremos, nacionalidad. En efecto, la traducción puede entenderse como un pretexto para marcar diferencias y ser útil a la sociedad. No sólo implica contar lo que ha pasado con la "legalidad" y el "decoro" 
que requiere la "verdad" de la historia, sino que también contiene una clara dimensión instructiva. La utilidad ilustrada -tan valorada en la época- entra en escena con el propósito de tejer una red de relaciones entre las ventajas de la imparcialidad, la parcialidad y el amor a la patria. Los elogios a la imparcialidad conferirán al concepto una carga de prestigio que se ve subrayada por las virtudes del buen ciudadano y la contraposición al espíritu de partido, opuesto al interés general y la justicia. La idea de imparcialidad es, después de todo, pedagógica y patriótica. Aparecerá conectada, como veremos, con la satisfacción de los intereses generales de una sociedad y la "buena apariencia" de ésta.

En el Espíritu de los mejores diarios, un misterioso colaborador señalaba precisamente esas relaciones $y$, más específicamente, la correspondencia entre imparcialidad y amor a la patria, convirtiendo esa virtud en dependiente de los caracteres nacionales. Aprovechaba también la ocasión para reivindicar la precisión y la justicia que debían predicar los historiadores, poniendo como ejemplo a los cronistas romanos, valorados como testigos de lo acontecido - como sucedía en el pensamiento renacentista-, como garantía para construir una historia "perfecta". Además, denunciaba especialmente las situaciones en las que los historiadores se dejaban arrastrar por el espíritu de partido (ESPÍRITU 1787, p. 26-27).

Otro historiador, especialmente interesado en el mundo americano y en la apología de España, nos brinda en sus escritos un uso muy clarividente del concepto. Se trata del ministro riojano Martín Fernández de Navarrete, conocido escritor que dedicó sus esfuerzos a la historia marítima española y a examinar los legajos de Cristóbal Colón. En su discurso, la idea de imparcialidad aparece vinculada a la escritura de la historia, en estrecha relación con la condición de extranjero. En mayor medida que el nacional, los extranjeros deformaría y confundiría los acontecimientos del pasado; de esa forma, se equivocarían y "trastruecan no sólo los hechos sino hasta la nomenclatura material de nuestros pueblos" (FERNÁNDEZ DE NAVARRETE 1826, p. LVIII).

La noción de extranjero aparecerá repetidamente vinculada, por tanto, a la idea de parcialidad. El extranjero es parcial y esa asociación tiene una carga eminentemente negativa. Junto a Fernández de Navarrete se sitúa toda una serie de opiniones que irían en la misma línea. Este es el caso del ilustrado José de Olmeda y León (1740-1805), un traductor, jurista y oidor de la Audiencia de Sevilla que -como tantos otros apologistas se encontraba preocupado por 
el honor de la nación española. Olmeda acusaba a los extranjeros, entre otras cosas, de haber hecho poco favor a la memoria de Fernando el Católico porque "no podían mirar con imparcialidad su glorioso reinado" (OLMEDA Y LEÓN 1771, p. 332).

Los lectores del Siglo de las Luces estuvieron muy familiarizados con la idea de parcial, antónimo del término que nos ocupa. El diccionario del jesuita Esteban Terreros (1786-1793) recoge la idea de parcial como derivado del latín "sectarius", con el significado de "afecto, apasionado o partidario, de una causa", una especie de antónimo de "rectitud". El Diccionario de la Real Academia -en la tercera edición de 1791, reducida a un tomo - incluye "parcialidad" como sinónimo de "facción o partido" (REAL ACADEMIA 1791, p. 626). Este significado se mantiene, asimismo, en la quinta edición de 1817. Aparece, junto a ella, la forma adjetiva y el verbo "parcializar" con el significado de "aplicar alguna cosa más a uno que a otro, por especial afecto o parcialidad" (REAL ACADEMIA 1817, p. 639).

La parcialidad se anuda con la problemática de los caracteres nacionales. Muchos ilustrados la rechazarán cuando la noción se sitúe en estrecho diálogo con la vanidad o el narcisismo. El abate y lingüista conquense Lorenzo Hervás criticaba, precisamente, cómo la parcialidad influía en aquellos que escribían sobre el pasado. Consideraba la parcialidad una "peste" común de los historiadores que se veían cegados por el amor a la patria, aunque reconocía alguna excepción y, precisamente, española. Aprovechaba para elogiar al cronista Juan de Mariana, afirmando que había escrito sobre España "con la indiferencia de un extranjero" aunque en realidad no lo fuera (HERVÁs; PANDURO 1789, p. 185). El caso de Juan de Mariana reviste cierta especificidad, tanto por el éxito editorial de su crónica y su alta consideración entre los historiadores de la época, como por el uso del concepto de imparcialidad, que lo alejaba de cualquier sospecha de sesgo en su escritura a favor de su nación. En este caso, y en contradicción con otros testimonios, Hervás invierte la ecuación entre extranjero y parcialidad, considerando a Mariana un buen ejemplo de cómo un nacional podía alejarse de la pasión propia de su patria. A ojos de Hervás, la imparcialidad y la crítica de Mariana se manifestaban en el hecho de que el propio autor no se hubiese referido en su obra a la dinastía de los Austrias "porque temió que la adulación a sus hijos podría obligarle a quemar demasiado incienso sobre el sepulcro de sus padres" (HERVÁS; PANDURO 1789, p. 185).

Patriotismo, parcialidad y los valores del buen ciudadano caminarán juntos en la literatura de la época, como también lo demostrará 
la sátira La derrota de los pedantes (MORATÍN 1789, p. 72). El patriotismo es, en ocasiones, parcialidad e ignorancia. Por el contrario, la imparcialidad equiparada a la verdad es el lenguaje del buen ciudadano y del amor a la patria. Cabría distinguir, pues, una corriente crítica con respecto al concepto de parcialidad, visto como antagonista de la felicidad pública y el interés general, valores e intereses fundamentales del discurso ilustrado. Esta cuestión estaba imbricada también con la escritura apologética de la literatura y la historia, con la polémica levantada a lo largo de aquellos textos publicados por Cañuelo en El censor. Veamos, en esa misma línea, otro ejemplo del uso de "parcialidad" en los escritos del duque de Híjar desde un acentuado tono crítico. Agustín de Silva Fernández apoya un punto de vista particular en un discurso en el que la parcialidad se disfraza de enemigo a combatir. El duque de Híjar pone el acento en las consecuencias negativas que la acompañarían, debido a su asociación con el patriotismo y el amor propio, y la opondrían a la verdad. No sólo tendrían su reflejo en el terreno de la justicia, sino también en el ámbito político, siendo, en suma, un "velo que perturba la vista para ver el verdadero mérito de las cosas" (HÍJAR 1792, p. 4-5).

Cabe recordar que otra de las acepciones del adjetivo "parcial" que figuraba en los diccionarios de la época era la de "amigo, familiar, nacional y sociable", mientras que el sustantivo significaba "trato amistoso o sociabilidad". Es el atributo que usa, por ejemplo, el jesuita pamplonés Idiáquez para referirse a su compañero de orden Juan Andrés: "el señor abate Juan Andrés [...] se declara muy parcial de los árabes y respira a favor de ella en una especie de arrebatamiento" (IDIÁQUEZ 1788, p. 1). Esa cualidad no se atribuye solo a individuos, sino también a objetos y con una carga positiva. Es lo que se constata en esta expresión: "el cielo se declara parcial de nuestra navegación" (ISLA 1790, p. 168). Manifestarse favorable o "parcial" a Cristóbal Colón, por ejemplo, no era óbice para que el historiador fuera más o menos imparcial en su escritura (DIARIO DE MADRID 1789, p. 857-858).

\section{La imparcialidad y la crítica}

El espíritu crítico es un componente esencial del lenguaje ilustrado sin el cual no podría comprenderse la idea de imparcialidad ni sus derivados semánticos. La emergencia de la conciencia nacional y de los textos útiles a "nuestros compatriotas" se vinculará con la la- 
bor crítica sobre los documentos en la construcción de la historia (PÉREZ MAGALLÓN 2002, p. 170; MESTRE 2002, p. 417-434; MESTRE 1986, p. 111-132). Esa crítica se entiende como un juicio riguroso que permite esclarecer la veracidad de los datos y su interpretación, una forma de distinguir lo verdadero de lo falso. De esa forma, la crítica era una forma de conocimiento y una de las premisas que ayudaría a construir la ciencia histórica a lo largo del siglo XIX.

La escritura de la historia, tal y como se concebía en la Ilustración, era una narración basada en una metodología concreta. Sostenida en los documentos, era dependiente de la erudición y de la crítica, de un examen racional de los conocimientos heredados, fruto del trabajo en archivos y bibliotecas en los que se analizaban documentos, inscripciones u otros restos del pasado. Del mismo modo, se la ha entendido como producto de las políticas culturales del gobierno y de complejas relaciones de poder. Como ya lo han señalado los especialistas, nunca podrá entenderse la actitud de los ilustrados españoles sin tener en cuenta la política cultural de los Borbones. En el análisis de sus posturas cabría diferenciar tanto sus propósitos e intenciones como la base intelectual y metodológica, basada en la crítica textual y el análisis de fuentes primarias (STIFFONI 1989; ALBADALEJO 2007). ${ }^{4}$

La crítica, acompañada del adjetivo "imparcial", definirá la actitud intelectual del hombre de las Luces (ÁLVAREZ DE MIRANDA 1992, p. 511-543). En el terreno de la escritura de la historia, ese espíritu se manifestará con claridad en las críticas, por ejemplo, a la obra de Annio de Viterbo (KAGAN 2010, p. 84.). Sus premisas permitirán, también, ensalzar la historia nacional frente a la posición sesgada adoptada en algunos textos extranjeros; aunque, en realidad, rechazar la autenticidad y la veracidad de crónicas y documentos pudiera significar, simple y llanamente, sustituirlos por otros (MESTRE 1990, p. 21-60; GARCÍA HERNÁN 2004, p. 127-194).

La ambigüedad de los historiadores a la hora de abordar ciertas tradiciones - en particular, cuando entraban en juego las glorias nacionales y los orígenes míticos de ciertas tradiciones y grupos sociales- pone de manifiesto precisamente las limitaciones de la crítica. Este impulso crítico y racional no dejaba de implicar, por otra parte, una toma de posición sobre una cuestión concreta, así como la escritura de relatos con una marcada dimensión mitológica.

Distinguir la historia fabulosa y legendaria más "típica" de la

\begin{abstract}
4 - La dificultad de hacer compatible la "historia crítica" con la necesidad de objetividad y las exigencias gubernamentales puede verse a lo largo del siglo en la relación estrecha que mantuvo D. Juan José de Austria con los renovadores de la historiografía.
\end{abstract}


historiografía barroca de la historia dieciochesca planteaba, en realidad, un problema político, sobre todo cuando afectaba a los orígenes de la nación, las tradiciones religiosas y la conquista. La crítica a las crónicas renacentistas como fuentes fiables para abordar la conquista americana fue una tónica común en muchos ilustrados. Un ejemplo se halla en el Memorial literario, donde se publica un texto sobre la impresión de la Historia de la Conquista del Perú de Beauchamp (MEMORIAL LITERARIO 1808, p. 241). En ese texto se rechaza contundentemente a los primeros cronistas por "participar de su parcialidad", de "todas las preocupaciones de la nación" y del tiempo que escribieron.

La "crítica imparcial" expresaba en realidad diferencias entre diversos modos de practicar y escribir historia, proyectando de alguna manera las experiencias y opiniones de unos sobre otros. Los ilustrados, al compás de los debates y las corrientes intelectuales europeas, protegieron su manera de entender el pasado y la imagen nacional frente a las posturas y las múltiples caras de la otredad. La ideología que subyace al concepto siempre es la que tienen otros $y$, al fin y al cabo, esa es una manera de universalizar o promocionar una creencia o valor afín a un grupo social (EAGLETON 2005, p. 20-24).

Se sabe que, en aquel momento, la condición de historiador, su responsabilidad y pretensiones eran motivo de polémica intelectual entre diversos grupos políticos. Algunos adjudicaban a la profesión el rol de distinguir las certezas de las verosimilitudes y las falsedades. Otros destacaban, más bien, la necesidad de pintar con exactitud la realidad (NUIX 1782, p. 43). ¿Qué se podía esperar de un historiador? Una respuesta puede encontrarse en uno de los periódicos más característicos del momento, el Espíritu de los mejores diarios, editado por Cristóbal Cladera, traductor mallorquín y un buen conocedor de las hazañas de los descubridores y conquistadores españoles y portugueses. Aunque se tratara del año 1788, las páginas del diario ofrecían a los lectores una magnífica definición de objetividad histórica (ESPÍRITU 1788, p. 360): lo menos deseable que podía hacer un historiador era, precisamente, tomar partido.

¿Cómo distinguir, sin embargo, al historiador imparcial del que se posiciona abiertamente? Cinco años antes, Francisco Masdeu, el jesuita catalán que escribió en su etapa italiana la Historia de la cultura española, no dudaba en sentenciar que los historiadores más imparciales eran los españoles. Esta era una virtud con la que se construía una "diferencia", aunque también permitiera distinguir un 
segundo grupo de historiadores extranjeros más y menos favorables a España. En la pluma de Masdeu, el concepto de imparcialidad adquiere un matiz moral y ambiguo, pero no se concibe como una cualidad de la investigación de la que el historiador estuviera investido. Asimismo, Masdeu reconoce la amplia carga de las historias falsas y míticas heredadas desde el Renacimiento, algo que, sin embargo, no era exclusivo de España (MASDEU 1783, p. 189). Así, los eruditos eran conscientes, de los peligros de la parcialidad y de las inclinaciones personales que podían detectarse en el trabajo histórico. José Ortiz Sanz, presbítero y traductor valenciano, se refiere precisamente a la condición de historiador como la más "infeliz y peligrosa" de la intelectualidad. Ello debido a las contundentes críticas que podía sufrir, bien fuera por su estilo, su parcialidad o inexactitud.

De todos modos, la "historia crítica" no conllevó en absoluto la desaparición de las construcciones fantásticas y mitológicas que se habían difundido en las crónicas renacentistas sobre el mundo americano. Los intelectuales no abandonaron una lectura de la conquista en clave épica y eurocéntrica, presidida por la idea de que "unos cuantos aventureros", unos pocos hombres excepcionales, héroes valientes y aguerridos, habían enaltecido la monarquía, propagado la verdadera fe, la cultura y el progreso occidental. La pretensión de desmentir la "Leyenda Negra," aspecto en el que ya insistía el madrileño Antonio de Solís en su célebre Historia de México, continuó con un vigor renovado en el nuevo contexto de la segunda mitad del siglo XVIII.

La cuestión americana se encontraba muy unida a las reflexiones que los ilustrados hacían sobre el pasado español. Un debate político e intelectual en la época consistió en dilucidar qué historias sobre América eran más exactas o fieles a la verdad: las producidas por misioneros, algunos afamados cronistas y soldados del Renacimiento, exploradores, viajeros u otros eruditos contemporáneos (CAÑIZARES ESGUERRA 2007, p. 63; ESTEVE BARBA 1992). Las pinturas sobre la conquista de México y Perú ponían en juego el honor, la opinión y la imagen de la monarquía española y la de sus héroes. La necesidad de acomodar esos aspectos a la política cultural ilustrada puede rastrearse, efectivamente, a lo largo de la literatura del momento. Esa preocupación perdurará hasta bien entrado el siglo XIX. Así puede constatarse en la edición madrileña de Antonio de Solís de 1840 (LINARES 1840, p. 6).

Esa literatura épica anudaba en su seno los conceptos de verdad, justicia e imparcialidad. De esa constelación de ideas nacía la 
legitimidad del relato de la conquista como narración colonialista y nacional, ya en aquel momento popular y mitologizada en muchos otros espacios de la vida pública, como el teatro y la iconografía (ARACIL VARÓN 2009; KOHUT 1992; RIVERA AYALA 2009; PERALTA RUÍZ 2006, p. 215-253). En la misma línea se encuentra la traducción de Juan Corradi, quien había vertido al castellano la obra del pedagogo y distinguido representante de la Ilustración alemana, Joachim Heinrich Campe. En el texto --conocido a lo largo del siglo liberal a través de sus distintas ediciones y dirigido de forma prioritaria al mundo infantil-Campe dejaba muy perfilado el significado y la aplicación de la idea de imparcialidad y parcialidad, preguntándose si era posible leer sin sentir cierta incomodidad las "calumnias" que los extranjeros habían escrito sobre España. En ese sentido, afirmaba que "quando la parcialidad, la malicia o la envidia dirigen la pluma del historiador [...] sólo se encuentra una caprichosa compilación de hechos desfigurados, que suelen ser manantial de preocupaciones y falsas ideas" (CORRADI 1803, p. 142).

El traductor es perfectamente consciente del problema. El pasado, según en manos de quien se colocara, podía ser peligroso, deformarse y perder su esencial función instructiva e identificativa. El compendio original de Campe -dedicado al retrato de las figuras individuales de la conquista y el descubrimiento- no era imparcial, esto es, patriótico, a ojos de Corradi. Así, la historia producida por algunos extranjeros podía provocar cierto sentimiento de incomodidad e indignación. No era justa con España. La historia extranjera no toda, evidentemente, pero sí una parte importante de ella- destruía los valores básicos y las tradiciones en las que se sustentaba esa visión de la conquista dulce, épica y cómoda.

Otro ejemplo contundente podemos encontrarlo en la obra de Pedro de Estala, un polifacético intelectual nacido en la localidad manchega de Daimiel. Entre sus variadas actividades literarias, tradujo un compendio de viajes que había sido escrito originalmente por el religioso francés Joseph de La Porte. Hacia 1799 se imprimían algunos tomos de su obra El viajero universal, un texto instructivo que Godoy llegó a comparar con la obra de Feijoó (ARENAS CRUZ 2003 , p. 441). Estala no se alejaba mucho de algunas opiniones ya comentadas anteriormente. Pero eso sí, confesaba, en primer lugar, que su escritura se explicaba por su "amor a la verdad" y no a la parcialidad nacional (ESTALA 1799, p. 206-207). Como exigía Estala, la imparcialidad y la crítica se convertían en condiciones necesarias 
para que los historiadores compusieran sus historias de América. Su posición era, antes que filosófica, historiográfica y política. Como otros muchos historiadores españoles, el literato Pedro de Estala apelaba a la imparcialidad como elemento necesario para escribir la historia de América y la de España, desde una perspectiva política.

Añadiremos un ejemplo más, protagonizado por un hombre de finales de siglo, el monje jerónimo Fernando Zevallos. Zevallos, representante notorio del pensamiento "conservador" dieciochesco, también comulgaba con las heroicidades de los conquistadores, como tantos otros contemporáneos. Una de sus intenciones fue la de dibujar una idea de parcialidad entendida como oposición al gobierno de España. La idea de parcialidad también podía aplicarse a un español en concreto, de marcado espíritu crítico, que representaba un obstáculo para la construcción del relato épico de la conquista: Bartolomé de Las Casas. Cualquier lector era capaz de percibir el "espíritu de partido" y el "ardor" que movía la pluma del dominico sevillano, en opinión del monje (ZEVALLOS 1774-1776, p. 306-334).

La exaltación y legitimación de los acontecimientos de 1492 se escondían bajo la idea de imparcialidad y patriotismo. Los ejemplos continúan a lo largo del siglo XIX y cruzan el océano, aunque con circunstancias históricas marcadamente distintas. El periodista liberal catalán Gil Gelpi y Ferro, dueño y director del diario cubano La prensa, publicó en las décadas de 1860 y 1870 diversos escritos sobre Cuba y las colonias españolas. En uno de ellos, escribía las siguientes palabras: "el hombre que examina los hechos de los descubridores del Nuevo Mundo con imparcialidad e inteligencia, conoce que a bordo de aquellos buques no había más que héroes" (GELPÍ Y FERRO 1864, p. 32). Justificaba la objetividad de su texto -bastante dudosa, por cierto, como lo señala Ricardo Rivas- aludiendo a que había utilizado fuentes diversas y de una ideología diferente a la suya (RIVAS 1996, p. 181).

Concluiré con otra referencia de las que fueron colonias españolas. En plena época liberal, un diccionario aparecía publicado con una serie de artículos históricos y geográficos relativos a la República Mexicana. Entre ellos, nos llama la atención uno dedicado al asalto de Chapultepec, la batalla librada contra Estados Unidos en la ciudad de México. El hecho es interpretado como una desgracia para las tropas mexicanas, pues "mil soldados americanos han vencido [...] a seis mil mexicanos. En este punto nosotros hemos querido conservar una severa imparcialidad, mortificando en la mayor parte 
de las ocasiones nuestro amor propio nacional" (OROZCO Y BERRA 1856). Se trata de un fragmento destacable en la medida en que, al contrario que en otros textos, se opta por una visión que no va de la mano del interés en promover la grandeza del estado mexicano -como sucede en el caso español-, sino que, más bien, ofrece un panorama derrotista que explota el famoso tópico colonial de que unos pocos conquistaron a unos muchos.

\section{Consideraciones finales}

Muchos investigadores han insistido en demostrar cómo el lenguaje refleja todo tipo de ideologías. Los frecuentes usos de "imparcialidad" en la segunda mitad del siglo XVIII caminan en esa dirección, ya que remiten a la construcción de una "diferencia" que dependía de la mirada propia y la ajena, de las nociones culturales de nacional y extranjero. La figura del historiador "imparcial" era reclamada desde casi cualquier tribuna - prólogos, obras de teatro, prensa, compendios, disertaciones, diccionarios-, mientras el concepto se rodeaba de cierta carga de prestigio y verdad. Sólo el historiador que escribiera la historia apropiada, la que abordaba con justicia el pasado "español", merecería ser considerado imparcial.

En ese contexto preciso, la mayor parte de los textos proyectan una idea de imparcialidad vinculada a hablar favorablemente de los españoles (RODRÍGUEZ MOHEDANO 1769, p. 21-109). Esta concepción se apoya, pues, en una literatura que enaltece la bondad, la sinceridad y la exactitud como rasgos característicos de los historiadores de la metrópoli. Los testimonios que honraban a la nación española contra las críticas extranjeras eran entendidos como un ejercicio de imparcialidad, aunque existieran voces críticas que señalaban el patriotismo como posible causa "deformante" de los retratos del pasado. Conviene resaltar, por otro lado, que no todas las opiniones circularon en los mismos términos o son equiparables, sobre todo cuando el historiador manejaba contextos y tendencias políticas muy diversas.

No existe, en realidad, una única manera de entender la imparcialidad en un momento histórico concreto; ni tampoco de entender la patria -sobre todo en esta coyuntura histórica, en la que el concepto de "patria" y el de "nación" eran todavía ambiguos, contradictorios y polisémicos (FUENTES 2013, p. 169-196; ÁLVAREZ DE MIRANDA 1992, p. 211-269; FERNÁNDEZ ALBADALEJO 2001, p. 485-532; THOMPSON 1995, p. 125-159) - ni, mucho menos, el sentimiento que debe alber- 
garse por ella. Sin embargo, la idea de imparcialidad cumple la función de legitimar como apropiadas y positivas ciertas visiones sacralizadas y heroicas del pasado, ciertos personajes e imaginarios unidos a ellos. La empresa americana como relato épico en el que refulge la figura del héroe conquistador es, precisamente, uno de los mejores ejemplos.

Pese a la existencia de criterios diferentes y discursos que caminan en otra dirección, puede afirmarse que existe un cierto consenso sobre el significado del término. La idea de la imparcialidad surge, entonces, como garante de la identidad nacional en la escritura histórica y funciona como fuente de legitimidad con la que fabricar, y en último término, sustentar los discursos sobre el "Nuevo Mundo". Y ello pese al clima intelectual imperante de crisis colonial y a la controversia existente sobre la escritura de la historia de América en las arenas del debate europeo.

No parece casualidad, sin embargo, el aumento del uso de la noción en las últimas décadas del s. XVIII frente a etapas anteriores. Tampoco parece una casualidad que la idea se desprendiera en 1803 -al menos académicamente hablando- de su carga más negativa o antiilustrada. $Y$ ello sucede precisamente en un momento en el que Francisco Sánchez Blanco (2007, p. 5) identifica una de las etapas más vitales de la Ilustración, entre 1795 y 1805 . No será, por tanto, con el pensamiento liberal que el concepto de imparcialidad adquirirá su significado definitivo, un significado que se tiñe, a partir de ese momento, de una semántica únicamente positiva.

Pesara más o menos el amor a la patria en la escritura de la historia, las reflexiones sobre la imparcialidad demuestran que los debates sobre el distanciamiento, la exactitud y la justicia en la escritura de la historia vienen, en realidad, de muy lejos. Así las cosas, los eruditos españoles pondrán en duda la imparcialidad de algunos historiadores que distorsionan el pasado proyectando, a su parecer, elementos ajenos al mismo. Esta pretensión -ya se debiera, en su opinión, a la pasión, la envidia, el interés o el desconocimiento- fue un privilegio de una minoría social muy diversa, con intereses marcadamente diversos -ideologías a favor y en contra de los valores de la Ilustración-, que decidió otorgar nueva fuerza al término y determinar cómo elaborar ese relato y en qué términos hacerlo.

Quizá no sólo la historia se plasma a través de variados conceptos e ideas, sino que esos mismos sustentan una historia propia. Pese a las contradicciones que se manifiestan en su uso, la utilización de la idea de imparcialidad proporciona una base firme para que los indivi- 
duos puedan forjar una identidad más o menos coherente (EAGLETON 2005, p. 36) y legitimar, al mismo tiempo, su escritura histórica. La idea de imparcialidad, al calor de la polémica en torno al "Nuevo Mundo", y la controversia acerca de los caracteres nacionales sostienen imaginarios colectivos y esconden una manera particular en la que historia y política (con)fluyen permanentemente. He tratado de poner de relieve su incidencia en el vocabulario ilustrado, su dimensión ideológica y escasa transparencia en manos de individuos y en contextos muy concretos. No sólo se usó para designar cierta lealtad y justicia hacia el pasado "nacional"; de alguna manera, su uso también implicó la exclusión de otras visiones del pasado, de otros hombres y mujeres, conquistados y conquistadores, que participaron en los acontecimientos de 1492. Su ausencia en los relatos supuso la negación o minimización de las muertes, de la conflictividad social y de las rebeliones sucedidas a lo largo del complejísimo proceso histórico que fue la conquista de América.

\section{REFERÊNCIAS BIBLIOGRÁFICAS}

ÁLVAREZ DE MIRANDA, Pedro. Palabras e ideas, el léxico de la Ilustración en España (1680-1760). Madrid: Real Academia Española, 1992.

ARENAS CRUZ, María Elena. Pedro Estala, Vida y obra. Una aportación a la teoría literaria del siglo XVIII español. Madrid: Consejo Superior de Investigaciones Científicas, 2003.

BAS MARTÍN, Nicolás. Juan Bautista Muñoz (1745-1799) y la fundación del Archivo de Indias. Valencia: Biblioteca Valenciana, 2000.

BODEKER, Hans Erich. Historia de los conceptos como historia de la teoría. Historia de la teoría como historia de los conceptos. Una aproximación tentativa. In: FERNÁNDEZ SEBASTIAN, Javier; CAPELLÁN DE MIGUEL, Gonzalo. Conceptos políticos, tiempo e historia. Santander: Ediciones Universidad de Cantabria, 2013, p. 3-30.

BOLUFER, Mónica. Civilización, costumbres y política en la literatura de viajes a España en el siglo XVIII. Estudis, Revista de Historia Moderna, n. 29, p. 255-300, 2003. 
. Del salón a la asamblea: sociabilidad, espacio público y ámbito privado (siglos XVII-XVIII). Saitabi, n. 56, p. 121$148,2006$.

CAÑIZARES ESGUERRA, Jorge. Cómo escribir la historia del Nuevo Mundo, historiografías, epistemologías e identidades en el mundo atlántico del siglo XVIII. México: Fondo de Cultura Económica, 2007.

CASTILLA URBANO, Francisco (Ed.). Discursos legitimadores de la conquista y colonización de América. Alcalá de Henares: Servicio de Publicaciones de la Universidad de Alcalá, 2014.

CHECA BELTRÁN, José (Ed). Lecturas del legado español en la Europa ilustrada. Madrid/Frankfurt: Iberoamericana/ Vervuert, 2007.

CORRADI, Juan. Descubrimiento y conquista de la América o Compendio de la Historia General del Nuevo Mundo por el autor del Nuevo Robinson, traducido del francés, corregido y mejorado. Madrid: Imprenta Real, 1803.

DIARIO de Madrid. 3 de agosto de 1789.

DIZ, Alejandro. La visión de Europa y América en la España Ilustrada. In: CHARTIER, Roger; FEROS, Antonio (dirs.). Europa, América y el mundo: tiempos históricos. Madrid: Marcial Pons, 2006, p. 171-190.

DOSSE, François. La marcha de las ideas: historia de los intelectuales, historia intelectual. Valencia: Publicacions Universitat de València, 2007.

EAGLETON, Terry. Ideología. Una introducción. Barcelona: Editorial Paidós, 2005.

ESCOIQUIZ, Juan. México conquistada, poema heroico dedicado al rey nuestro señor. Madrid: Imprenta Real, 1789. 
ESPÍRITU de los mejores diarios que se publican en Europa. 9 de julio de 1787.

ESPÍRITU de los mejores diarios literarios publicados en Europa. 8 de septiembre de 1788.

ESTALA, Pedro. El viajero universal o noticia del mundo antiguo y nuevo. Madrid: Imprenta de Villalpando, 1799.

ESTEVE BARBA, Francisco. Historiografía indiana. Madrid: Gredos, 1992.

FERNÁNDEZ SEBASTIÁN, Javier; FUENTES, Juan Francisco (dirs.). Diccionario político y social del siglo XIX español. Madrid: Alianza, 2002.

FERNÁNDEZ ALBADALEJO, Pablo. Materia de España: cultura política e identidad en la España Moderna. Madrid: Marcial Pons, 2007.

- Dinastía y comunidad política: el momento de la patria. In: FERNÁNDEZ ALBADALEJO, Pablo (dir.). Dinastía y memoria de nación en la España del siglo XVIII. Madrid: Marcial Pons, 2001, p. 485-532.

FERNÁNDEZ DE NAVARRETE, Martín. Discurso preliminar o introducción a la colección de los viajes y descubrimientos que hicieron por mar los españoles desde fines del siglo XV. Madrid: Imprenta Real, 1826.

FORNER, Juan Pablo. Oración apologética por la España y su mérito literario: para que sirva de exornación al discurso leído por el abate Denina en la Academia de Ciencias de Berlín, respondiendo a la cuestión qué se debe a España. Madrid: Imprenta Real, 1786.

FUENTES, Juan Francisco. Conceptos previos: patria y nación en los orígenes de la España contemporánea. In: MORALES MOYA, Antonio; FUSI, Juan Pablo; BLAS GUERRERO, Andrés (eds.). Historia de la nación y del nacionalismo español. 
Barcelona: Galaxia Gutemberg, 2013, p. 169-196.

FONTANA, Josep. Historia: análisis del pasado y proyecto social. Barcelona: Crítica, 1999.

GARCÍA HERNAN, Enrique. Construcción de las historias de España en los siglos XVII y XVIII. In: GARCÍA CÁRCEL, Ricardo (coord.). La construcción de las Historias de España. Madrid: Marcial Pons, Fundación Carolina, Centro de Estudios Hispánicos e Iberoamericanos, 2004, p. 127-194.

GELPÍ Y FERRO, Gil. Estudios sobre la América. Conquista y colonización, gobiernos coloniales y gobiernos independientes. La Habana: El Iris, 1864.

GERBI, Antonello. La disputa del Nuevo Mundo: historia de una polémica: 1750-1900. México: Fondo de Cultura Económica, 1982.

HERVÁS Y PANDURO, Lorenzo. Historia de la vida del hombre. Madrid: Imprenta de Aznar, 1789.

HÍJAR, Agustín Pedro Silva de Fernández de Híjar, Duque de. Discurso sobre la necesidad y utilidad de las leyes $y$ como deben respetarse y cumplirse pronunciado en el Real Consejo de las Ordenes por su presidente, el dos de enero de 1792. Madrid: Imprenta de Sancha, 1792.

IDIÁQUEZ, Francisco Xavier. Disertación histórica sobre las sociedades, colegios y academias de la Europa y en particular de España. Antes de la invasión de los moros y aún antes del nacimiento de Mahoma. Madrid: Imprenta de la Viuda de Ibarra y Compañía, 1788.

ISLA, José Francisco de. Aventuras de Gil Blas de Santillana robadas a España y adoptadas en Francia por Monsieur Lesage. Madrid: Imprenta de la Viuda e Hijo de Marín, 1790.

JENKINS, Keith. Repensar la historia. Madrid: Siglo XXI Editores, 2009. 
KAGAN, Richard. Los cronistas y la corona: la política de la historia en España en las Edades Media y Moderna. Madrid: Centro de Estudios Europa Hispánica, Marcial Pons Historia, 2010.

KOHUT, Karl (ed.). De conquistadores y conquistados: realidad, justificación, representación. Frankfurt Am Main, Madrid: Iberoamericana Vervuert, 1992.

LINARES, Wenceslao. Historia de la conquista, población, progresos de América Septentrional, conocida por el nombre de Nueva España. Nueva edición ilustrada con notas. Madrid: Imprenta de Francisco Oliva, 1840.

LÓPEZ CORDÓN, María Victoria. De monarquía a nación: la imagen histórica de España en el siglo de la Ilustración. Norba: Revista de historia, n. 19, p. 151-172, 2006.

MASDEU, Francisco de. Historia crítica de España y de la cultura española. Obra compuesta y publicada en italiano. Madrid: Imprenta de Antonio de Sancha, 1783.

MESTRE, Antonio. Historia crítica y reformismo en la Ilustración española. In: ALBEROLA ROMÁ, Armando; LA PARRA LÓPEZ, Emilio (Eds.). La Ilustración española: Actas del Coloquio Internacional celebrado en Alicante. Alicante: Diputación Provincial de Alicante, Instituto Alicantino de Cultura Juan Gil Albert, 1986, p. 111-132.

- Historia crítica y reforma cultural. In: PEREIRA IGLESIAS, José Luis (coord.). Felipe V de Borbón (17011746). Actas del Congreso de San Fernando (Cádiz). Córdoba: Servicio de Publicaciones, Fundación Municipal de Cultura del Ayuntamiento de San Fernando, 2002, p. 417-434.

Apología y crítica de España en el siglo XVIII. Madrid: Marcial Pons, 2003.

MORATÍN, Leandro. La derrota de los pedantes. Madrid: Oficina de Benito Cano, 1789. 
NOVICK, Peter. Ese noble sueño: la objetividad y la historia profesional norteamericana. México: Instituto Mora, 1997.

NUIX, Juan. Reflexiones imparciales sobre la humanidad de los españoles en Indias. Madrid: Joaquín Ibarra, 1782.

OLIVE, José Felipe de. Diversión de las personas de talento por el autor del Correo literario de Gerona. Murcia: Oficina de Juan Vicente Teruel, 1800.

OLMEDA Y LEÓN, Joseph. Elementos del derecho público de la paz y de la guerra, ilustrados con noticias históricas, leyes y doctrinadas del derecho español. Madrid: Imprenta Viuda de Manuel Fernández, 1771.

OROZCO $Y$ BERRA, Manuel. Apéndice al diccionario universal de historia y de geografía. México: Imprenta de J. M. Andrade y F. Escalante, 1856.

PAGDEN, Anthony. European encounters with the New World, from Renaissance to Romanticism. Yale: Yale University Press, 1993.

PERALTA RUIZ, Víctor. Antonio Porlier y la historiografía americanista a finales del siglo XVIII. In: PERALTA RUIZ, Víctor. Patrones, clientes y amigos: el poder burocrático indiano en la España del siglo XVIII. Madrid: Consejo Superior de Investigaciones Científicas, 2006, p. 215- 253.

PÉREZ MAGALLÓN, Jesús. Construyendo la modernidad: la cultura española en el tiempo de los novatores (1675-1725). Madrid: Consejo Superior de Investigaciones Científicas, 2002.

REAL ACADEMIA ESPAÑOLA. Diccionario de lengua castellana, reducido a un tomo para su más fácil uso. Madrid: Joaquín Ibarra, 1791.

Diccionario de la lengua castellana en que se explica el verdadero sentido de las voces, su naturaleza y calidad, con las phrases o modos de hablar, los proverbios 0 
refranes y otras cosas convenientes al uso de la lengua. Tomo IV, Madrid, Imprenta de la Real Academia Española, Herederos de Francisco del Hierro, 1734.

Diccionario de la lengua castellana compuesto por la Real Academia Española. Cuarta Edición, Madrid, Viuda de Joaquín Ibarra, 1803.

Diccionario de la lengua castellana por la Real Academia Española. Quinta Edición, Madrid, Imprenta Real, 1817.

RIVAS, Ricardo Alberto. Historiografía de América entre 18651941. Trabajos y comunicaciones, n. 24, p. 177-203, 1996.

RIVERA AYALA, Sergio. El discurso colonial en los textos novohispanos: espacio, cuerpo y poder. Sufolk: Tamesis, 2009.

RODRÍGUEZ LASO, Nicolás. Elogio histórico del excelentísimo señor duque de Almodóvar, director de la Real Academia de la Historia, leído en la Junta del 11 de julio de 1794. Madrid: Imprenta de Sancha, 1795.

RODRÍGUEZ MOHEDANO, Rafael y Pedro. Historia literaria de España desde su primera población hasta nuestros días. Segunda edición corregida por los autores. Madrid, Imprenta de Francisco Xavier García, 1769.

SÁNCHEZ BLANCO, Francisco. La Ilustración goyesca. La cultura en España durante el reinado de Carlos IV (1788-1808). Madrid: CSIC, Centro de Estudios Políticos y Constitucionales, 2007.

SANTANA PÉREZ, Juan Manuel. Viera y Clavijo: Historiador ilustrado del Atlántico. Historia da historiografia, n. 23, p. 43-63, 2017.

SHERIDAN, Thomas. A complete Dictionary of the English Language. London: Charles Dilly, 1785. 
STIFFONI, Giovanni. Verità della storia e ragioni del potere nella Spagna del primo Settecento. Milano: Franco Angeli Storia, 1989.

TERREROS Y PANDO, Esteban de. Diccionario castellano. Madrid: Viuda de Ibarra, 1784.

THOMPSON, Irving A. A. Castile, Spain and the monarchy: the political community from patria natural to patria national. In: KAGAN, Richard L.; PARKER, Geoffrey (eds). Spain, Europe and the Atlantic world: Essays in honour of John H. Elliott, Cambridge: Cambridge University Press, 1995, p. 125-59.

VÉLEZ GIMÉNEZ, Palmira. La historiografía americanista en España (1755-1936). Madrid/Frankfurt: Iberoamericana/ Vervuert, 2007.

ZEVALLOS, Fernando. La falsa filosofía o el ateísmo, deísmo, materialismo y demás nuevas sectas convencidas de crimen de estado contra los soberanos y sus regalías. Madrid: Antonio Fernández, 1774-1776.

\section{AGRADECIMENTOS E INFORMAÇŌES}

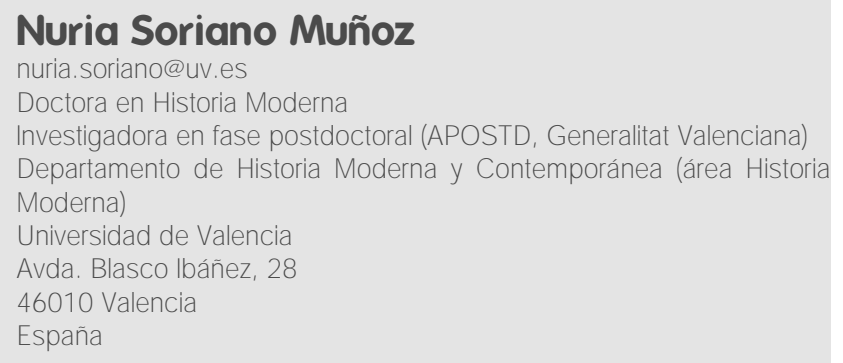

Este trabajo ha sido financiado gracias a una ayuda para investigadores en fase postdoctoral concedida por la Conselleria d'Educació, Investigació, Cultura i Esport de la Generalitat Valenciana (España) y el Fondo Social Europeo. Se integra en el proyecto de investigación "Nuevas perspectivas de historia social en los territorios hispánicos del Mediterráneo Occidental en la Edad Moderna" con referencia HAR2014-53298-C2-1." 